Article

\title{
Rapid Development of Microsatellite Markers with 454 Pyrosequencing in a Vulnerable Fish, the Mottled Skate, Raja pulchra
}

\author{
Jung-Ha Kang ${ }^{1}$, Jung-Youn Park ${ }^{1}$ and Hyun-Su Jo ${ }^{2, *}$ \\ 1 Biotechnology Research Division, NFRDI, Busan 619-705, Korea; \\ E-Mails: kjh0124@nfrdi.go.kr (J.-H.K.); jypark@nfrdi.go.kr (J.-Y.P.) \\ 2 Fisheries Resources and Environment Division, West Sea Fisheries Research Institute, NFRDI, \\ Incheon 400-420, Korea \\ * Author to whom correspondence should be addressed; E-Mail: hsjo@nfrdi.go.kr; \\ Tel.: +82-51-720-2462; Fax: +82-51-720-2456.
}

Received: 7 May 2012; in revised form: 5 June 2012 / Accepted: 6 June 2012 /

Published: 12 June 2012

\begin{abstract}
The mottled skate, Raja pulchra, is an economically valuable fish. However, due to a severe population decline, it is listed as a vulnerable species by the International Union for Conservation of Nature. To analyze its genetic structure and diversity, microsatellite markers were developed using 454 pyrosequencing. A total of 17,033 reads containing dinucleotide microsatellite repeat units (mean, 487 base pairs) were identified from 453,549 reads. Among 32 loci containing more than nine repeat units, 20 primer sets (62\%) produced strong PCR products, of which 14 were polymorphic. In an analysis of 60 individuals from two $R$. pulchra populations, the number of alleles per locus ranged from $1-10$, and the mean allelic richness was 4.7. No linkage disequilibrium was found between any pair of loci, indicating that the markers were independent. The Hardy-Weinberg equilibrium test showed significant deviation in two of the 28 single-loci after sequential Bonferroni's correction. Using 11 primer sets, cross-species amplification was demonstrated in nine related species from four families within two classes. Among the 11 loci amplified from three other Rajidae family species; three loci were polymorphic. A monomorphic locus was amplified in all three Rajidae family species and the Dasyatidae family. Two Rajidae polymorphic loci amplified monomorphic target DNAs in four species belonging to the Carcharhiniformes class, and another was polymorphic in two Carcharhiniformes species.
\end{abstract}


Keywords: Raja pulchra; pyrosequencing; microsatellite

\section{Introduction}

Many sharks and skates are particularly vulnerable to overfishing because of their large size, slow growth, late maturity and low fecundity. Among the 227 species in 25 genera of the family Rajidae, 11 skate species belonging to four genera have been identified in Korea to date. Skates are commercially important in Korea, and the mottled skate, Raja pulchra, is the most favored and valuable species because of its superior meat quality [1]. This species is one of the most expensive fishes sold in South Korea, reaching US \$10-30 per kilogram. This species is also valued in China and Japan for their dried wings and meat, but is less expensive (US \$5) than in South Korea.

Raja pulchra, a low-boreal subtropical species abundant in the coastal waters of some areas of Korea and Japan, is usually caught at a depth of about 5-100 m [2-4]. This species has been known to inhabit the East China Sea, the Yellow Sea, the East Sea, the Pacific coast of Japan, the southern Kurils, and a recent survey has shown that they are present off the coast of western Sakhalin [5,6].

Catch data from Korea shows a 90\% decline over a ten-year period. The average annual catch from 1991-1993 was 2700 metric tons, whereas the catch in 2011-2003 was 220 metric tons [7], reflecting a serious decline in the biomass collected. In China, there has been an overall reduction in all fish biomass due to overexploitation and heavy trawling within the mottled skate's range, as well as habitat degradation as a result of such fishing activities. The overall decline in numbers of this species has exceeded 30\% over the last 15 years (a period of three generations) [8]. As a result, the International Union for Conservation of Nature (IUCN) has designated it as "vulnerable" and in fact, the decline may be severe enough to warrant a status of "endangered" [8]. However, there are no conservation measures in place for this species. Further assessment and monitoring of catches in fisheries and population trends are required.

Microsatellite (MS) or simple sequence repeat (SSR) markers are versatile molecular tools for determining parentage, inferring genetic structure and gene flow patterns and for assessing the origins of introduced populations [9,10]. Traditionally, the isolation of MS DNA loci has relied on the screening of genomic libraries using repetitive probes and sequencing of positive clones to develop locus-specific primers. While effective in many applications, these cloning and sequencing procedures are tedious, labor-intensive and expensive [11,12].

Next generation sequencing (NGS) technologies have revolutionized many life science fields because of its rapid cost-efficient parallel processing of millions of templates [13]. NGS is capable of generating gigabases of sequence data in a single run, with individual reads long enough ( $>500 \mathrm{bp})$ to capture individual microsatellites and the flanking sequence for PCR primer design. Additionally, there is no need for enrichment because even a fraction of a run can provide sufficiently large numbers of random sequence reads to contain many thousands of microsatellites markers. Application of this technique to expressed genes would make it possible to develop panels of MS markers for genes underlying phenotypic variation [14].

Based on these advantages, this new technology is expected to replace conventional microsatellite isolation protocols [15], and there are increasing reports employing NGS MS markers in studies of 
mammals [16], plants [17,18], insects [19], and amphibians [20]. This new technology also has been applied in the development of microsatellite maker in marine organisms and was proven to be effective [21-24].

In this work, we carried out a global analysis of the repetitive fraction of the $R$. pulchra genome using NGS combined with the bioinformatics approach described above. This work will be useful for future resource management of this economically and ecologically important, but vulnerable, species.

\section{Results}

\subsection{Pyrosequencing, Repeat Identification and Classification}

NGS produced 453,549 reads with an average length of $487 \mathrm{bp} ; 4,305$ contiguous sequences (contigs) were constructed by Newbler (version 2.6; Roche) from these reads. The total number of bases was 2,024,317, and the largest contig was 16,906 bp. In addition, we found 307,931 unassembled singleton sequences for a total read of 150,038,230 bp. The total number of reads after trimming of low quality sequence was 288,854 , and the sum of the total reads was $148,321,261 \mathrm{bp}$ in length, which was used in a search for SSRs. The number of reads with dinucleotide repeat were: 4164 AT, 6544 CA, 6239 CT, and 86 GC repeats. The sequence and number of 2625 trinucleotide repeats are shown in Table 1.

Table 1. Sequencing statistics using 454 sequencing platforms.

\begin{tabular}{|c|c|c|c|}
\hline \multicolumn{3}{|c|}{ Primary sequence data } & No. \\
\hline \multicolumn{3}{|c|}{ Total number of reads } & 453,549 \\
\hline \multicolumn{3}{|c|}{ Total number of bases } & $221,052,902$ \\
\hline \multicolumn{3}{|c|}{ Number of contigs } & 4,305 \\
\hline \multicolumn{3}{|c|}{ Number of bases } & $2,024,317$ \\
\hline \multicolumn{3}{|c|}{ Number of Singleton } & 307,931 \\
\hline \multicolumn{3}{|c|}{ Total number of reads after trimmed } & 288,854 \\
\hline \multicolumn{3}{|c|}{ Total number of read-length after trimmed } & $148,321,261$ \\
\hline Di-nucleotide & No. & Di-nucleotide & No. \\
\hline AT & 4,164 & $\mathrm{CA}$ & 6,544 \\
\hline $\mathrm{CT}$ & 6,239 & $\mathrm{GC}$ & 86 \\
\hline Tri-nucleotide & No. & Tri-nucleotide & No. \\
\hline AAA & 8 & TAC & 8 \\
\hline AAT & 273 & TTG & 124 \\
\hline AAG & 164 & TTC & 102 \\
\hline AAC & 62 & TGA & 65 \\
\hline ATA & 238 & TGG & 124 \\
\hline ATG & 53 & TGC & 104 \\
\hline ATC & 89 & TCG & 3 \\
\hline AGA & 85 & TCC & 134 \\
\hline AGT & 10 & GAG & 117 \\
\hline $\mathrm{AGG}$ & 98 & GAC & 6 \\
\hline $\mathrm{AGC}$ & 82 & GTG & 54 \\
\hline ACA & 56 & GGG & 10 \\
\hline ACG & 2 & GGC & 32 \\
\hline ACC & 90 & GCG & 26 \\
\hline TAA & 261 & CAG & 103 \\
\hline TAG & 14 & CGG & 28 \\
\hline
\end{tabular}




\subsection{Selection and Characterization of the SSR}

Thirty two loci containing dinucleotide microsatellites with over nine repeats were selected for further evaluation. Primers were designed for these loci and tested in four individuals. Twenty primer sets $(62 \%)$ produced strongly amplified PCR products, and 14 showed clear amplification with polymorphic patterns. However, no clear genotype pattern was obtained for five loci, and Rp19-nfrdi was monomorphic in all of the tested individuals. The primer sequences, repeat motifs, annealing temperatures, PCR ranges, number of alleles, and GenBank accession numbers for the 15 new microsatellite loci are summarized in Table 2. The number of alleles per locus varied from one (at Rp19-nfrdi) to ten (at Rp11-nfrdi) in a total of 60 tested individuals.

Table 2. Characteristics of microsatellite loci from Raja pulchra.

\begin{tabular}{|c|c|c|c|c|c|c|c|}
\hline Locus & & Primer Sequence $\left(5^{\prime} \rightarrow 3^{\prime}\right)$ & Motif & AT & $\begin{array}{l}\text { Allele } \\
\text { Size }\end{array}$ & $\begin{array}{l}\text { No. of } \\
\text { Allele }\end{array}$ & $\begin{array}{c}\text { GenBank } \\
\text { Accession } \\
\text { No. }\end{array}$ \\
\hline Rp03-nfrdi & $\begin{array}{l}\mathrm{F} \\
\mathrm{R}\end{array}$ & $\begin{array}{l}\text { 6-FAM ACTGCCTAGGATGATGATGAAG } \\
\text { TCTATATCCCTCCACTTCCTTG }\end{array}$ & $(\mathrm{AT})_{13}$ & 54 & 94-106 & 4 & JQ433555 \\
\hline Rp11-nfrdi & $\begin{array}{l}\mathrm{F} \\
\mathrm{R}\end{array}$ & $\begin{array}{l}\text { 6-FAM ATACACTCATCACTCACACCCC } \\
\text { GTGGGTTAGTGCTCTTGTTCTC }\end{array}$ & $(\mathrm{CA})_{15}$ & 61 & $108-134$ & 10 & JQ433556 \\
\hline Rp16-nfrdi & $\begin{array}{l}\mathrm{F} \\
\mathrm{R}\end{array}$ & $\begin{array}{l}\text { 6-FAM AGGAAGGCTTCAGCACATAAT } \\
\text { CTCATCTGGAAGAGCACACAC }\end{array}$ & $(\mathrm{TG})_{13}$ & 54 & $102-108$ & 4 & JQ433557 \\
\hline Rp18-nfrdi & $\begin{array}{l}\mathrm{F} \\
\mathrm{R}\end{array}$ & $\begin{array}{l}\text { 6-FAM ATTCCCTGATACAGATGGAGG } \\
\text { TAAACTGTTTGCTCСТCTCTCC }\end{array}$ & $(\mathrm{CA})_{16}$ & 61 & $113-145$ & 9 & JQ433558 \\
\hline Rp19-nfrdi & $\begin{array}{l}\mathrm{F} \\
\mathrm{R}\end{array}$ & $\begin{array}{l}\text { 6-FAM CAGACAATGAAACTCAACAGGA } \\
\text { TCTAACTTCAATTAACCTTCGCA }\end{array}$ & $(\mathrm{AG})_{12}$ & 54 & 96 & 1 & JQ433569 \\
\hline Rp22-nfrdi & $\begin{array}{l}\mathrm{F} \\
\mathrm{R}\end{array}$ & $\begin{array}{l}\text { 6-FAM ATAGCATGAATACAATCCCAGG } \\
\text { GATGATCACTTGGATTCCTGAT }\end{array}$ & $(\mathrm{AG})_{12}$ & 54 & $102-108$ & 3 & JQ433559 \\
\hline Rp24-nfrdi & $\begin{array}{l}\mathrm{F} \\
\mathrm{R}\end{array}$ & $\begin{array}{l}\text { 6-FAM TGTTCTACAAGACACAAGGCAG } \\
\text { ATTCCTCAGCTAACATCTCCAA }\end{array}$ & $(\mathrm{AG})_{12}$ & 54 & $105-107$ & 2 & JQ433560 \\
\hline Rp27-nfrdi & $\begin{array}{l}\mathrm{F} \\
\mathrm{R}\end{array}$ & $\begin{array}{l}\text { NED CATATTCATCATCAATTAAATCTGTC } \\
\text { GCATATCCTTTGTCTGTCCAT }\end{array}$ & $(\mathrm{TG})_{9}$ & 54 & $224-232$ & 3 & JQ433561 \\
\hline Rp30-nfrdi & $\begin{array}{l}\mathrm{F} \\
\mathrm{R}\end{array}$ & $\begin{array}{l}\text { NED CGTGTATATGTATGTGTGCATGT } \\
\text { GCAGAAGCACTACAGAATGTTT }\end{array}$ & $(\mathrm{TG})_{11}$ & 61 & $216-230$ & 7 & JQ433562 \\
\hline Rp34-nfrdi & $\begin{array}{l}\mathrm{F} \\
\mathrm{R}\end{array}$ & $\begin{array}{l}\text { NED TATGATCCATACAATCGCAAAA } \\
\text { CAAATAGCAAACGACCTACACC }\end{array}$ & $(\mathrm{TG})_{9}$ & 54 & $240-250$ & 6 & JQ433563 \\
\hline Rp35-nfrdi & $\begin{array}{l}\mathrm{F} \\
\mathrm{R}\end{array}$ & $\begin{array}{l}\text { NED CTTACTGGTGAGGAATCTGAGC } \\
\text { GCATACACTCCACACACCAC }\end{array}$ & $(\mathrm{TG})_{9}$ & 61 & $226-236$ & 5 & JQ433564 \\
\hline Rp39-nfrdi & $\begin{array}{l}\mathrm{F} \\
\mathrm{R}\end{array}$ & $\begin{array}{l}\text { HEX GCTTGGTTTTCTGAAATCAGTG } \\
\text { ATAAAATTGCAGGGAGAATGC }\end{array}$ & $(\mathrm{AT})_{13}$ & 61 & $150-166$ & 5 & JQ433565 \\
\hline Rp43-nfrdi & $\begin{array}{l}\mathrm{F} \\
\mathrm{R}\end{array}$ & $\begin{array}{l}\text { HEX CTCCTGCCTTTGCTATGTGT } \\
\text { GACTTTTCAGCGACAGTCTTCT }\end{array}$ & $(\mathrm{TG})_{15}$ & 61 & $154-162$ & 5 & JQ433566 \\
\hline Rp44-nfrdi & $\begin{array}{l}\mathrm{F} \\
\mathrm{R}\end{array}$ & $\begin{array}{l}\text { HEX ACATGGTCACGAGTAGAATGTG } \\
\text { TTCAGACCCTATTCAAAATGCT }\end{array}$ & $(\mathrm{CA})_{16}$ & 54 & 149-161 & 6 & JQ433567 \\
\hline Rp53-nfrdi & $\begin{array}{l}\mathrm{F} \\
\mathrm{R}\end{array}$ & $\begin{array}{l}\text { HEX GGACGGAATCCTTCTTTAAACT } \\
\text { CTTTGTGCCTCTTTGTTAAACC }\end{array}$ & $(\mathrm{AG})_{15}$ & 54 & $140-148$ & 5 & JQ433568 \\
\hline
\end{tabular}


Table 3. Variability at fourteen microsatellite loci in Raja pulchra populations from Korea.

\begin{tabular}{|c|c|c|c|c|c|c|c|c|c|c|c|c|c|c|c|c|}
\hline \multirow[t]{2}{*}{ Population } & & \multicolumn{14}{|c|}{ Microsatellite Loci } & \multirow[t]{2}{*}{$\begin{array}{l}\text { Mean of } \\
\text { All Loci. }\end{array}$} \\
\hline & & Rp3 § & Rp11 $^{\S}$ & Rp16 & Rp18 $^{\S}$ & Rp22 & Rp24 & Rp27 & Rp30 & Rp34 & Rp35 & Rp39 & Rp43 ${ }^{\S}$ & Rp44 & Rp53 & \\
\hline \multirow[t]{7}{*}{$\mathrm{DC}$} & $N$ & 28 & 30 & 30 & 30 & 30 & 30 & 30 & 30 & 30 & 30 & 30 & 29 & 30 & 30 & 29.8 \\
\hline & $\mathrm{Na}$ & 3 & 7 & 4 & 7 & 3 & 2 & 3 & 6 & 6 & 5 & 4 & 5 & 6 & 5 & 4.7 \\
\hline & $A_{R}$ & 3.00 & 6.64 & 3.83 & 6.78 & 3.00 & 2.00 & 2.83 & 5.80 & 6.00 & 5.00 & 4.00 & 4.97 & 5.64 & 5.00 & 4.61 \\
\hline & $R$ & $94-106$ & $108-134$ & $102-108$ & $113-145$ & $102-108$ & $105-107$ & $224-232$ & $216-228$ & $240-250$ & $226-236$ & $150-162$ & $154-162$ & $149-161$ & $140-148$ & \\
\hline & Ho & 0.393 & 0.400 & 0.567 & 0.433 & 0.600 & 0.567 & 0.333 & 0.667 & 1.000 & 0.800 & 0.567 & 0.276 & 0.433 & 0.800 & 0.560 \\
\hline & $\mathrm{He}$ & 0.511 & 0.690 & 0.584 & 0.676 & 0.671 & 0.503 & 0.288 & 0.666 & 0.788 & 0.773 & 0.657 & 0.477 & 0.443 & 0.769 & 0.607 \\
\hline & $F_{I S}$ & 0.231 & 0.421 & 0.029 & 0.359 & 0.105 & -0.126 & -0.159 & -0.002 & -0.269 & -0.035 & 0.138 & 0.422 & 0.022 & -0.040 & 0.078 \\
\hline \multirow[t]{7}{*}{ HS } & $N$ & 29 & 30 & 30 & 30 & 30 & 30 & 30 & 30 & 30 & 30 & 30 & 25 & 30 & 30 & 29.6 \\
\hline & $\mathrm{Na}$ & 4 & 10 & 4 & 8 & 3 & 2 & 2 & 6 & 6 & 5 & 5 & 4 & 5 & 5 & 4.9 \\
\hline & $A_{R}$ & 4.00 & 9.79 & 3.98 & 7.62 & 3.00 & 2.00 & 2.00 & 5.81 & 6.00 & 5.00 & 5.00 & 4.00 & 4.80 & 4.83 & 4.84 \\
\hline & $R$ & 94-106 & $108-134$ & $102-108$ & $113-133$ & $102-108$ & $105-107$ & $230-232$ & $216-230$ & $240-250$ & $226-236$ & $150-166$ & $156-162$ & 149-161 & $140-148$ & \\
\hline & Ho & 0.276 & 0.800 & 0.700 & 0.567 & 0.667 & 0.367 & 0.400 & 0.700 & 0.567 & 0.867 & 0.467 & 0.240 & 0.633 & 0.833 & 0.577 \\
\hline & $\mathrm{He}$ & 0.603 & 0.797 & 0.595 & 0.732 & 0.608 & 0.481 & 0.364 & 0.676 & 0.746 & 0.801 & 0.494 & 0.487 & 0.573 & 0.702 & 0.619 \\
\hline & $F_{I S}$ & $0.542 *$ & -0.004 & -0.177 & 0.226 & -0.097 & 0.237 & -0.099 & -0.035 & 0.241 & -0.082 & 0.056 & $0.508 *$ & -0.104 & -0.187 & -0.002 \\
\hline Mean of & $N$ & 28.5 & 30.0 & 30.0 & 30.0 & 30.0 & 30.0 & 30.0 & 30.0 & 30.0 & 30.0 & 30.0 & 27.0 & 30.0 & 30.0 & \\
\hline \multirow[t]{6}{*}{ All Pops. } & $\mathrm{Na}$ & 3.5 & 8.5 & 4.0 & 7.5 & 3.0 & 2.0 & 2.5 & 6.0 & 6.0 & 5.0 & 4.5 & 4.5 & 5.5 & 5.0 & \\
\hline & $A_{R}$ & 3.50 & 8.22 & 3.90 & 7.20 & 3.00 & 2.00 & 2.42 & 5.81 & 6.00 & 5.00 & 4.50 & 4.48 & 5.22 & 4.92 & \\
\hline & $R$ & $94-106$ & $108-134$ & $102-108$ & $113-145$ & $102-108$ & $105-107$ & $224-232$ & $216-230$ & $240-250$ & $226-236$ & $150-166$ & $154-162$ & $149-161$ & $140-148$ & \\
\hline & Ho & 0.334 & 0.600 & 0.633 & 0.500 & 0.633 & 0.467 & 0.367 & 0.683 & 0.783 & 0.833 & 0.517 & 0.258 & 0.533 & 0.817 & \\
\hline & He & 0.557 & 0.744 & 0.589 & 0.704 & 0.639 & 0.492 & 0.326 & 0.671 & 0.767 & 0.787 & 0.576 & 0.482 & 0.508 & 0.736 & \\
\hline & $F_{I S}$ & 0.387 & 0.208 & -0.074 & 0.293 & 0.004 & 0.056 & -0.129 & -0.018 & -0.014 & -0.058 & 0.097 & 0.465 & -0.041 & -0.113 & \\
\hline
\end{tabular}

Number of samples $(\mathrm{N})$; number of alleles per locus $(\mathrm{Na})$; allelic richness $\left(\mathrm{A}_{R}\right)$; allelic size range $(\mathrm{R})$; expected heterozygosity $(\mathrm{He})$; and observed heterozygosity $(\mathrm{Ho})$ are given for each population and locus. ${ }^{*}$ Not in conformity with Hardy-Weinberg equilibrium $\left(p<0.005\right.$, Bonferroni-corrected value). ${ }^{\S}$ Microsatellite loci revealed the presence of null alleles with MICRO-CHEKER 2.2.3. 


\subsection{Genetic Diversity of Raja pulchra Populations}

Table 3 summarizes the genetic characterization indices estimated for the two skate ray populations. Allelic richness per locus ranged from 2-9.8 in the two populations. The mean allelic richness was 4.7. The average number of alleles among all populations was 4.8. In total, there were 13 unique alleles, five from the Daecheong-do population and eight from the Heuksan-do population. No linkage disequilibrium was found between any pair of loci $(p>0.05)$, indicating that the markers were independent. The Hardy-Weinberg equilibrium (HWE) test, indicating the deviation from expected heterozygosity, showed significant deviation in two (Rp3-nfrdi and Rp43-nfrdi) of the 28 single-loci in the Heuksando population after sequential Bonferroni's correction. Null alleles were presumed in four (Rp3, Rp11, Rp18 and Rp43-nfrdi) of 14 loci. No genetic differentiation between DC and HS populations was detected by $F_{S T}(=0.013)$ using all 14 microsatellite markers.

\subsection{Cross-Species Amplification}

Cross-species amplification of 11 loci was conducted in nine related species belonging to four families within two classes, as shown in Table 4. These are representative species of cartilaginous fish. All of the 11 loci amplified the target DNAs from the three other fish species, Okamejei boesemani, O. kenojei and O. acutispina that belong to the same family, Rajidae. Among these loci, Rp11, Rp16 and Rp53 were polymorphic in all three species. The locus Rp16, which was monomorphic in R. pulchra, was also monomorphic in all three species. Additionally, the monomorphic locus Rp16 was amplified in two fish species, Dasyatis akajei and Uroplophus aurantiacus, belonging to the Dasyatidae family. In contrast, no amplification of other loci was observed in either or both of these species. The Rp3 and Rp16 loci that were polymorphic in the Rajidae family amplified monomorphic target DNAs in four fish species belonging to the class Carcharhiniformes, and the Rp35 locus was polymorphic in two species belonging to this class (Table 4).

Table 4. Screening of cross-species amplified microsatellite loci developed in Raja pulchra in related-species, skate and shark.

Microsatellite DNA Markers

Species Name

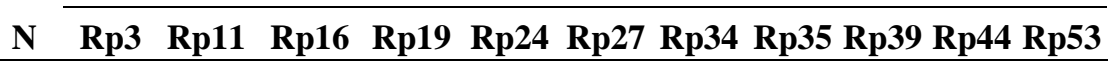

Rajiformes (Skate)

Rajidae Raja pulchra

Okamejei boesemani

Okamejei kenojei

Okamejei acutispina

Dasyatididae Dasyatis akajei

Urolophus aurantiacus

Carcharhiniformes (Shark)

Scyliorhinidae Cephaloscylium isabaellum

Scyliorhinus torazame

Triakidae Mustelus manazo

Triakis scyllium

\begin{tabular}{cccccccccccc}
60 & $\odot$ & $\odot$ & $\odot$ & $\circ$ & $\odot$ & $\odot$ & $\odot$ & $\odot$ & $\odot$ & $\odot$ & $\odot$ \\
3 & $\odot$ & $\odot$ & $\odot$ & $\circ$ & $\odot$ & $\odot$ & $\mathrm{X}$ & $\odot$ & $\odot$ & $\odot$ & $\odot$ \\
2 & $\odot$ & $\odot$ & $\odot$ & $\circ$ & $\circ$ & $\mathrm{X}$ & $\circ$ & $\circ$ & $\circ$ & $\circ$ & $\odot$ \\
3 & $\circ$ & $\odot$ & $\odot$ & $\circ$ & $\circ$ & $\mathrm{X}$ & $\circ$ & $\odot$ & $\odot$ & $\odot$ & $\odot$ \\
1 & $\mathrm{X}$ & $\circ$ & $\mathrm{X}$ & $\circ$ & $\mathrm{X}$ & $\mathrm{X}$ & $\mathrm{X}$ & $\mathrm{X}$ & $\mathrm{X}$ & $\mathrm{X}$ & $\circ$ \\
4 & $\odot$ & $\mathrm{X}$ & $\mathrm{X}$ & $\circ$ & $\mathrm{X}$ & $\mathrm{X}$ & $\mathrm{X}$ & $\mathrm{X}$ & $\mathrm{X}$ & $\circ$ & $\mathrm{X}$ \\
& & & & & & & & & & & \\
2 & $\circ$ & $\mathrm{X}$ & $\circ$ & $\odot$ & $\mathrm{X}$ & $\mathrm{X}$ & $\circ$ & $\odot$ & $\mathrm{X}$ & $\mathrm{X}$ & $\mathrm{X}$ \\
1 & $\circ$ & $\circ$ & $\circ$ & $\mathrm{X}$ & $\mathrm{X}$ & $\mathrm{X}$ & $\mathrm{X}$ & $\circ$ & $\mathrm{X}$ & $\mathrm{X}$ & $\mathrm{X}$ \\
2 & $\circ$ & $\circ$ & $\circ$ & $\odot$ & $\mathrm{X}$ & $\mathrm{X}$ & $\circ$ & $\odot$ & $\mathrm{X}$ & $\circ$ & $\mathrm{X}$ \\
1 & $\circ$ & $\mathrm{X}$ & $\circ$ & $\circ$ & $\mathrm{X}$ & $\mathrm{X}$ & $\mathrm{X}$ & $\circ$ & $\mathrm{X}$ & $\circ$ & $\mathrm{X}$ \\
\hline
\end{tabular}

$\mathrm{N}$ : number of individual; ๑: PCR amplified and polymorphic; ○: PCR amplified and monomorphic; X: non-PCR amplified. 


\section{Discussion}

Among 11 skate species identified in Korea so far, R. pulchra is the most economically important species, and it is consumed raw or as fermented fish. It inhabits coastal areas around the Korean Peninsula and was extremely common about 20 years ago in the Yellow Sea, especially around the Daecheong-do and Heuksan-do Islands of Korea. As in other skates, reproduction of R. pulchra is oviparous, and the number of eggs in each spawning is less than 250 [4]. Because there has been a $>90 \%$ catch decrease over the past ten years, it has been placed on the "vulnerable" species list by the IUCN [8]. Therefore, it is necessary to understand the genetic structure and population diversity for future management and resource restoration.

MS markers have many advantages over other molecular markers for the study of population structure and diversity [25]. However, the cloning and sequencing processes commonly used in MS marker development are time consuming and costly, often with positive clone yields as low as $0.03 \%$ [26].

NGS has recently been applied in the development of MS markers in many organisms, greatly reducing the cost, labor and time required [13,15,16,27]. This method has been shown to be more effective when enriched DNA libraries are used for sequencing [28]. Despite the advantages, the development of MS markers using NGS in aquatic organisms has been limited, but has been proven to be effective in recent publications [21-24,29].

In addition to speed and cost-effectiveness, NGS offers high flexibility in primer design because a large number of reads and sequences containing SSRs and loci with the proper repeat units can be selected. In our study, 17,033 (5.5\%) from a total of 312,290 contigs contained dinucleotide SSRs, and 33 loci containing a minimum of nine repeat units were used for primer design, which is only $0.2 \%$ of the identified SSRs. In the analysis of MS markers reported in plant, only $1 \%$ of polymorphic loci identified using NGS were selected by stringent criteria for primer design, compared with $20 \%$ of SSRs discovered using a traditional cloning and sequencing process were selected for primer design [30].

To select optimal primers from a large number of candidates, high-quality standards can be applied in loci selection, which can increase the success rate and reduce the time, labor and cost of marker development. For instance, to minimize the risk of null allele amplification, 454 sequence alignments can be used to design primers using loci with a reasonably high depth of coverage at both primer-annealing sites, and that show no evidence of SNPs within the regions [31]. In our study, $20(62 \%)$ primer sets among 32 loci containing a minimum of nine repeat units produced amplified PCR products, and 14 (70\%) of them were polymorphic.

After sequential Bonferroni correction for multiple tests, significant deviations from HWE in the direction of heterozygote deficiency were detected at only two (Rp3-nfrdi and Rp43-nfrdi) of the 14 tested loci in the Heuksan-do population. Generally, heterozygote deficiencies increase due to factors such as inbreeding, substructuring of the population sample, or the presence of null alleles. Indeed, our Microchecker analysis revealed the presence of null alleles at four loci, including Rp3-nfrdi and Rp43-nfrdi. The level of genetic diversity (mean $\mathrm{Ho}=0.57, \mathrm{He}=0.61$; mean allelic number $=4.7$ ) in this study was slightly higher than that of the common skate, Dipturus batis (mean Ho $=0.35$, $H e=0.36$; mean allelic number $=3.5$ ) [32]. No genetic differentiation between populations by $F_{S T}$ may suggest that the two populations can be regarded as one population. However, differentiation of genetically related skate population by distance has been observed in northeast Atlantic continental 
shelf [32]. To reduce the time and cost of MS marker development, pre-existing markers from related species have been applied to the study of many animal, fungus, plant and fish species [33,34]. Moreover, cross-species markers can be used for the identification of invading species and the identification of parental origin in hybrid fish [35]. Although the cross-species transferability of MS markers is unevenly distributed among taxa, over $40 \%$ and $25 \%$ of polymorphic marker transfers have been observed in fish of different genera within the same family, and of families within same order, respectively [33].

With large numbers of SSR candidates identified by pyrosequencing, the development of cross-species markers has been attempted in diverse organisms [36]. The markers developed in this study were tested for cross-species amplification and possibility of finding universal markers for cartilaginous fish with available fish samples. Among the ten markers polymorphic in $R$. pulchra, four (40\%) were polymorphic in other species within same family, which is comparable to previous data [33]. However, none of them showed any polymorphic amplification of targets in specimens belonging to different families within the same species. One interesting finding was that loci Rp16 and Rp35, which do not amplify the target sequences in the family Dasyatididae, produced monomorphic or polymorphic PCR products in Carcharhiniformes. Although the numbers of genera and samples for each genus are limited, these results suggest the possibility that cross-species polymorphic markers can be developed in fish species using the pyrosequencing technique with large number of SSR candidates for marker development.

The rapid population decline of $R$. pulchra around the Korean Peninsula, especially in the Yellow Sea, is due to many factors such as overfishing and destruction of their natural habitat. However, there have been no conservation measures in place for this species. Therefore, the molecular markers developed in this study will be useful for future assessment and monitoring of population trends of this species. In addition, this study suggests that pyrosequencing methods will be useful for SSR development in aquatic organisms, and may be preferable to the traditional labor- and time-intensive cloning methods.

\section{Experimental Section}

\subsection{Sample}

A total of 60 wild $R$. pulchra samples were collected around the Korean islands: 30 from the Daecheong-do population and 30 from the Heuksan-do population. Muscle tissue samples were preserved in $100 \%$ ethanol at the sampling site and then transported to the laboratory for DNA extraction. Total DNA was isolated from each sample using a MagExtractor MFX-6100 automated DNA extraction system (Toyobo, Osaka, Japan). The extracted genomic DNA was quantified using a Nanodrop ND-1000 spectrophotometer (Thermo Fisher Scientific, Barrington, IL, USA) and stored at $-20{ }^{\circ} \mathrm{C}$ until genomic DNA pyrosequencing. For the cross-species transferability test, DNA was extracted by the same method from ethanol-fixed tissues of nine related species belonging to four families within two classes that had been stored at the National Fisheries Research and Development Institute, Busan. 


\subsection{DNA Sequencing}

DNA sequencing was performed with 454 pyrosequencing on a Genome Sequencer FLX-454 System (GS FLX sequencer). Sample preparation and DNA sequencing was performed according to the manufacturer's instructions (Roche Diagnostics, Mannheim, Germany). DNA sample was prepared from one individual and sequencing was conducted using a half of a 454 plate at the National Instrumentation Center for Environmental Management (NICEM) of Seoul National University.

\subsection{De Novo Assembly and SSR Findings}

The raw reads from the GS FLX 454 were assembled using the Newbler 2.6 software and the assembled contigs consensus and unassembled singleton sequences were merged to discover SSRs on the genome sequence. The sequence was filtered with high quality score using the Less Useful Chunks Yank (LUCY) 1.20p. A modified "SSR_finder.pl" perl program was then used to detect di- and tri-SSR markers. A pair of primers flanking each SSR was designed using Primer3 software [37]. The primer redundancy was tested by using the BLAST available at NCBI [38] on the basis of $\leq 0.001$ e-values.

\subsection{PCR and Genotyping}

Newly-designed PCR primer pairs were tested to optimize annealing temperatures; a gradient PCR with a $50-60{ }^{\circ} \mathrm{C}$ annealing temperature range was performed on a set of samples from eight individuals. PCR amplification was performed in a $10 \mu \mathrm{L}$ reaction mixture containing $0.25 \mathrm{U}$ Ex taq DNA polymerase (TaKaRa Biomedical Inc., Shiga, Japan), $1 \times$ PCR buffer, $0.2 \mathrm{mM}$ dNTP mix, 10 pmol each primer (the forward primer of each pair was 5 '-end-labeled with 6-FAM, NED, and HEX dyes; PE Applied Biosystems), and 100 ng template DNA, using a PTC 200 DNA Engine (MJ Research, Waltham, MA, USA). PCR conditions were as follows: $11 \mathrm{~min}$ at $95{ }^{\circ} \mathrm{C}$, followed by 35 cycles of $1 \mathrm{~min}$ at $94{ }^{\circ} \mathrm{C}, 1 \mathrm{~min}$ at the annealing temperature listed in Table 2, and $1 \mathrm{~min}$ at $72{ }^{\circ} \mathrm{C}$, with a final extension of $5 \mathrm{~min}$ at $72{ }^{\circ} \mathrm{C}$. Microsatellite polymorphisms were screened using an ABI PRISM $3130 \mathrm{XL}$ automated DNA sequencer (Applied Biosystems), and alleles were designated according to PCR product size, relative to a molecular size marker (GENESCAN 400 HD [ROX]; PE Applied Biosystems).

\subsection{Statistical Analysis}

The number of alleles per locus, allele frequency, and heterozygosity were calculated using Arlequin version 3.0 [39]. Tests for population-wide linkage disequilibrium between pairs of loci and deviations from HWE were estimated using GENEPOP version 4.0 [40], and the adjusted $p$-values for both analyses were obtained using a sequential Bonferroni test for multiple comparisons. MICROCHECKER version 2.2.3 [41] was used to test the presence of null alleles. Allelic richness $\left(A_{R}\right)$ as a standardized measure of the number of alleles per locus, independent of the sample size, was calculated using FSTAT version 2.9.3 [42]. A possible geographical pattern in the distribution of genetic variability was analyzed through $F_{S T}$ estimates and genetic distances between each pair of populations. 


\section{Conclusions}

The pyrosequencing method was applied in the development of MS markers for R. pulchra, which is listed as a "vulnerable" species by the IUCN. A comparably high primer-to-marker conversion ratio (62\%) was achieved by this method. In the cross-species amplification, over $90 \%$ of the markers were amplified in the fishes belonging to the same family but the success ratio was much less in the different family. The molecular markers developed in this study can be used for future management of this economically and ecologically important species.

\section{Acknowledgment}

This work was supported by grants from the National Fisheries Research and Development Institute (NFRDI) in Korea (RP-2012-BT-013).

\section{References}

1. Jeong, C.H. A review of taxonomic studies and common names of rajid fishes (Elasmobranchii, Rajidae) from Korea. Koren J. Ichthyol. 1999, 11, 198-210.

2. Choi, Y.; Kim, J.H.; Park, J.Y. Marine Fishes of Korea; Kyo_Hak Publishing: Seoul, Korea, 2002.

3. Ishihara, H. Studies on the Systematics and Resources of the Skates (Rajidae) in the North Pacific Ocean. Ph.D. Dissertation, Tokyo University: Tokyo, Japan, 1990.

4. Yeon, I.J.; Hong, S.H.; Cha, H.K.; Kim, S.T. Feeding habitats of Raja pulchra in the Yellow Sea. Bull. Natl. Fish. Res. Dev. Inst. Korea 1999, 57, 1-11 (In Korean with English abstract).

5. Antonenko, D.V.S.; Solomatov, F.; Balanov, A.A.; Kim, S.T.; Kalchugin, P.V. Occurrence of Skate Raja pulchra (Rajidae, Rajiformes) in Russian waters of the sea of Japan. J. Ichthyol. 2011, 51, 426-431.

6. Ishihara, H. The Skates and Rays of the Western North Pacific: An Overview of Their Fisheries, Utilisation and Classification. In Elasmobranchs as Living Resources: Advances in Biology, Ecology, Systematic and the Status of Fisheries; Pratt, H.L., Gruber, S.H., Taniuchi, T., Eds.; NOAA Technical Report NMFS 90; U.S. Department of Commerce: Springfield, VA, USA, 1990.

7. Fisheries information service. Ministry for Food, Agriculture, Forestry and Fisheries: Gwacheon, Korea, 2009. Available online: http://www/fips.go.kr (accessed on 6 March 2012).

8. Ishihara, H.; Wang, Y.; Tanaka, S.; Nakaya, K.; Jeong, C.-H. Raja pulchra. IUCN Red List of Threatened Species. Version 2011.2. Available online: http://www.iucnredlist.org (accessed on 11 February 2012).

9. Chistiakov, D.A.; Hellemans, B.; Volckaert, F.A.M. Microsatellites and their genomic distribution, evolution, function and applications: A review with special reference to fish genetics. Aquaculture 2006, 255, 1-29.

10. Jarne, P.; Lagoda, P.J.L. Microsatellites from molecules to populations and back. Trends Ecol. Evol. 1996, 11, 424-429.

11. Hamilton, M.; Pincus, E.L.; di Fiore, A.; Fleischer, R.C. Universal linker and ligation procedures for construction of genomic DNA libraries enriched for microsatellites. Biotechniques 1999, 27, 500-507. 
12. Zane, L.; Bargelloni, L.; Patarnello, T. Strategies for microsatellite isolation: A review. Mol. Ecol. 2002, 11, 1-16.

13. Kircher, M.; Kelso, J. High-throughput DNA sequencing-concepts and limitations. BioEssays 2010, 32, 524-536.

14. Scaglione, D.; Acquadro, A.; Portis, E.; Taylor, C.A.; Lanteri, S.; Knapp, S.J. Ontology and diversity of transcript-associated microsatellites mined from a globe artichoke EST database. BMC Genomics 2009, 10, 1-17.

15. Abdelkrim, J.; Robertson, B.C.; Stanton, J.-A.L.; Gemmell, N.J. Fast, cost effective development of species-specific microsatellite markers by genomic sequencing. Biol. Tech. 2009, 46, 185-191.

16. Yu, J.N.; Won, C.; Jun, J.; Lim, Y.W.; Kwak, M. Fast and cost-effective mining of microsatellite markers using NGS technology: An example of a Korean Water Deer. Hydropotes Inermis Argyropus. PLoS One 2011, 6, doi:10.1371/journal.pone.0026933.

17. Setsuko, S.; Uchiyama, K.; Sugai, K.; Yoshimaru, H. Rapid development of microsatellite markers for Pandanus boninensis (Pandanaceae) by pyrosequencing technology. Am. J. Bot. 2012, 99, e33-e37.

18. McEwen, J.R.; Vamosi, J.C.; Rogers, S.M. Rapid isolation and cross-amplification of microsatellite markers in Plectritis congesta (Valerianaceae) with 454 sequencing. Am. J. Bot. 2011, 98, e369-e371.

19. Perry, J.C.; Rowe, L. Rapid microsatellite development for water striders by next-generation sequencing. J. Hered. 2010, 102, 125-129.

20. Castoe, T.A.; Poole, A.W.; Gu, W.; de Konig, A.P.J.; Daza, J.M.; Smith, E.N.; Pollock, D.D. Rapid identification of thousands of copperhead snake microsatellite loci from modest amounts of 454 shotgun genome sequence. Mol. Ecol. Resour. 2010, 10, 341-347.

21. Saarinen, E.V.; Austin, J.D. When technology meets conservation: Increased microsatellite marker production using 454 genome sequencing on the endangered Okaloosa Darter (Etheostoma okaloosae). J. Hered. 2010, 101, 784-788.

22. Wang, J.; Yu, X.; Zhao, K.; Zhang, Y.; Tong, J.; Peng, Z. Microsatellite development for an endangered bream Megalobrama Pellegrini (Teleostei, Cyprinidae) using 454 sequencing. Int. J. Mol. Sci. 2012, 13, 3009-3021.

23. Greenley, A.P.; Muguia-Vega, A.; Saenz-Arroyo, A.; Micheli, F. New tetranucleotide microsatellite loci in pink abalone (Haliotis corrugata) isolated via 454 pyrosequencing. Conserv. Genet. Resour. 2012, 4, 265-268.

24. Gardner, M.G.; Fitch, A.J.; Bertozzi, T.; Lowe, A.J. Rise of the machines-Recommendations for ecologists when using next generation sequencing for microsatellite development. Mol. Ecol. Resour. 2011, 11, 1093-1101.

25. Guichoux, E.; Lagache, L.; Wagner, S.; Chaumeil, P.; Léger, P.; Lepais, O.; Lepoittevin, C.; Malausa, T.; Revardel, E.; Salin, F.; et al. Current trends in microsatellite genotyping. Mol. Ecol. Resour. 2011, 211, 591-611.

26. Zane, L.; Bargelloni, L.; Patarnello, T. Strategies for microsatellite isolation: A review. Mol. Ecol. 2002, 11, 1-16. 
27. Csencsics, D.; Brodbeck, S.; Holderegger, R. Cost-effective, species-specific microsatellite development for the endangered Dwarf Bulrush (Typha minima) using next-generation sequencing technology. J. Hered. 2010, 101, 789-793.

28. Malausa, T.; Gilles, A.; Meglécz, E.; Blanquart, H.; Duthoy, S.; Costedoat, C.; Dubut, V.; Pech, N.; Castagnone-Sereno, P.; Délye, C.; et al. High-throughput microsatellite isolation through 454 GS-FLX Titanium pyrosequencing of enriched DNA libraries. Mol. Ecol. Resour. 2011, 11, 638-644.

29. Carvalho, D.C.; Beheregaray, L.B. Rapid development of microsatellites for the endangered Neotropical catfish Conorhynchus conirostris using a modest amount of 454 shot-gun pyrosequencing. Conserv. Genet. Resour. 2011, 3, 373-375.

30. Zalapa, J.E.; Cuevas, H.; Zhu, H.; Steffan, S.; Senalik, D.; Zeldin, E.; McCown, B.; Harbut, R.; Simon, P. Using next-generation sequencing approaches to isolate simple sequence repeat (SSR) loci in the plant sciences. Am. J. Bot. 2012, 99, 193-208.

31. Hoffman, J.I.; Nichols, H.J. A novel approach for mining polymorphic microsatellite markers in silico. PLoS One 2011, 6, doi:10.1371/journal.pone.0023283.

32. Griffiths, A.M.; Sims, D.W.; Cotterell, S.P.; Nagar, A.E.; Ellis, J.R.; Lynghammar, A.; McHugh, M.; Neat, F.C.; Pade, N.G.; Queiroz, N.; et al. Molecular markers reveal spatially segregated cryptic species in a critically endangered fish, the common skate (Dipturus batis). Proc. R. Soc. B 2010, 277, 1497-1503.

33. Barbará, T.; Palma-Silva, C.; Paggi, G.M.; Bered, F.; Fay, M.F.; Lexer, C. Cross-species transfer of nuclear microsatellite markers: Potential and limitations. Mol. Ecol. 2007, 16, 3759-3767.

34. Olivatti, A.M.; Boni, T.A.; Silva-Júnior, N.J.; Resende, L.V.; Gouveia, F.O.; Telles, M.P. Heterologous amplification and characterization of microsatellite markers in the Neotropical fish Leporinus friderici. Genet. Mol. Res. 2011, 10, 1403-1408.

35. Kang, J.H.; Kim, Y.K.; Park, J.Y.; An, C.M.; Nam, M.M.; Byun, S.G.; Lee, B.I.; Lee, J.H.; Choi, T.J. Microsatellite analysis as a tool for discriminating an interfamily hybrid between olive flounder and starry flounder. Genet. Mol. Res. 2011, 10, 2786-2794.

36. Delmas, C.E.; Lhuillier, E.; Pornon, A.; Escaravage, N. Isolation and characterization of microsatellite loci in Rhododendron ferrugineum (Ericaceae) using pyrosequencing technology. Am. J. Bot. 2011, 98, e120-e122.

37. Rozen, S.; Skaletsky, H.J. Primer3 on the WWW for general users and for biologist programmers. In Bioinformatics Methods and Protocols: Methods in Molecular Biology; Krawets, S., Misener, S., Eds.; Humana Press: Totowa, NJ, USA, 2000; pp. 365-386.

38. Basic Local Alignment Search Tool (BLAST). Available online: http://ncbi.nlm.nih.gov/blast (assessed on 9 October 2011).

39. Excoffier, L.; Lischer H.E.L. Arlequin suite ver. 3.5: A new series of programs to perform population genetics analyses under Linux and Windows. Mol. Ecol. Resour. 2010, 10, 564-567.

40. Raymond, M.; Rousset, F. Genepop (version 1.2), population genetics software for exact test and ecumenicism. J. Hered. 1995, 86, 248-249.

41. Van Oosterhout, C.; Hutchinson, W.F. Micro-checker: Software for identifying and correcting genotyping errors in microsatellite data. Mol. Ecol. Notes 2004, 4, 535-538. 
42. Goudet, J. FSTAT (version 1.2): A computer program to calculate F-statistics. J. Hered. 1995, 86, $485-486$.

(C) 2012 by the authors; licensee MDPI, Basel, Switzerland. This article is an open access article distributed under the terms and conditions of the Creative Commons Attribution license (http://creativecommons.org/licenses/by/3.0/). 